\title{
An erysipelas in a woman with pancreatitis
}

Ouiame EL Jouari*, Chaymae Jroundi, Ghita Senhaji, Amina Lamouaffaq, Sara Elloudi, Zakia Douhi, Hanane Baybay and Fatima ZMernissi Department of Dermatology, University Hospital Hassan II, FEZ, Morocco

\begin{abstract}
\section{Introduction}

Erysipelas is a non-necrotizing acute or subacute bacterial dermo-hypodermitis, most commonly caused by Group A hemolytic streptococcus, which are able to penetrate into soft tissue through a breach in the skin [1]. It is a relatively common pathology in adults. Sepsis during erysipelas is a rare complication of less than $1 \%$. It is well known that sepsis and hypertriglyceridemia are independent risk factors for pancreatitis [2]. The mechanism by which hypertriglyceridemia causes pancreatitis is unknown. We will raise an association between this infection and pancreatitis.
\end{abstract}

Sepsis during erysipelas is a rare complication of less than $1 \%$. Few studies have explored the metabolic response to sepsis. We report an unusual association of erysipelas with pancreatitis in an adult woman. We aim to explain the relationship between the diseases.

\section{Case presentation}

A 35-year-old patient with 4 days' history of erysipelas of the face on eczema lesions, complicated by acute vomiting and transfixing abdominal pain. The bioassay revealed predominantly PNN hyperleucocytosis, CRP elevated to $182 \mathrm{nmol} / \mathrm{L}$, lipaseemia to 4 times normal, hypertriglyceridemia to $2.29 \mathrm{~g}$ per liter, and HDL decreased to $0.24 \mathrm{mmol} / \mathrm{L}$. Abdominal CT showed B stage pancreatitis and the abdominal ultrasound was normal. The patient was placed under water and food restriction, triple antibiotherapy, basic ration, analgesics and gastric protection. The current decline is 3 months without recurrence or complications (Figures 1-3).

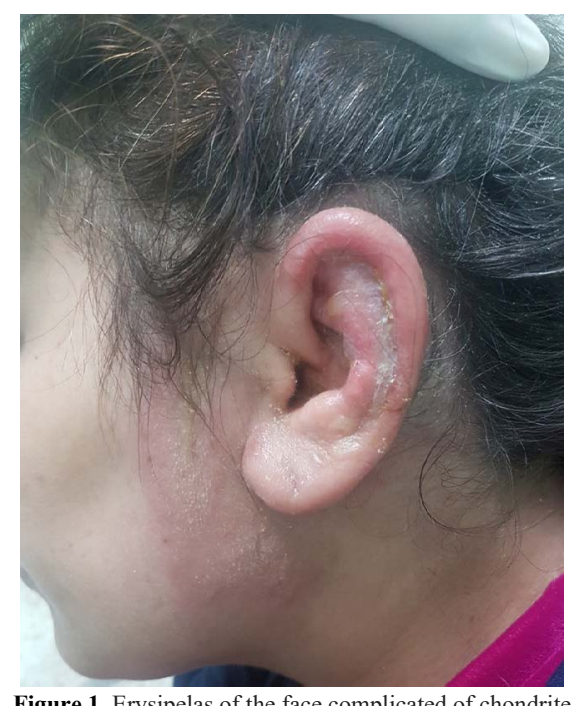

Figure 1. Erysipelas of the face complicated of chondrite

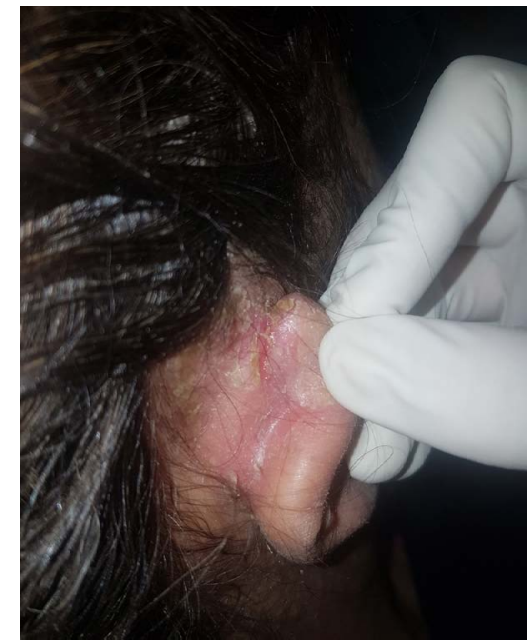

Figure 2. Retro-auricular involvement

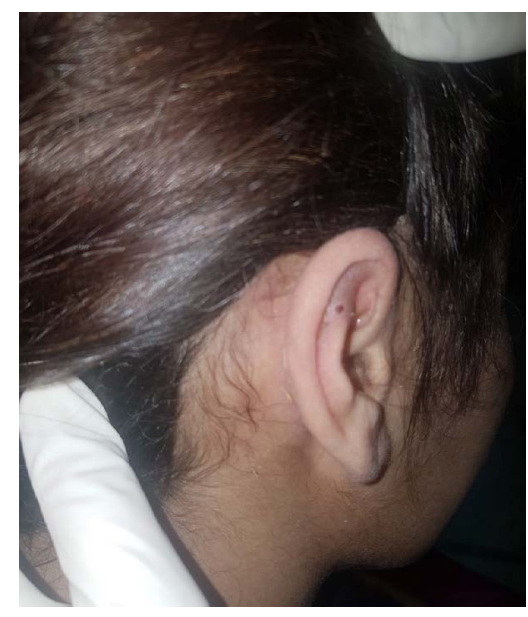

Figure 3. After 5 days of treatment

${ }^{\star}$ Correspondence to: Ouiame EL Jouari, Department of dermatology, University Hospital Hassan II, FEZ, Morocco, E-mail: eljouariouiame88@gmail.com

Received: November 27, 2018; Accepted: December 12, 2018; Published: December 17, 2018 


\section{Discussion}

Through this observation we will try to analyse the link between sepsis, hypertriglyceridemia and the development of pancreatitis. Few studies have explored the metabolic response to sepsis. Some authors have reported significantly elevated triglycerides and LDL levels and HDL decreased [3]. Other authors have noted low levels of total cholesterol, HDL, and LDL cholesterol in the initial phase of sepsis inversely associated with the severity of the disease [4]. Our results are consistent with those in the literature and highlight the usefulness of triglycerides levels as indicators of the risk of pancreatitis.

Hence the importance of managing triglycerides levels during sepsis to prevent pancreatitis and decrease the risk of complications such as recurrence of pancreatitis.

\section{Conclusion}

We report this case for the purpose of suspecting pancreatitis in any patient with erysipelas and transfixing abdominal pain. Also, we highlight the importance of managing triglycerides levels during sepsis to prevent pancreatitis and decrease the risk of complications such as recurrence of pancreatitis.

\section{References}

1. Maxwell-Scott H, Kandil H (2015) Diagnosis and management of cellulitis and erysipelas. Br J Hosp Med (Lond) 76: 114-117. [Crossref]

2. Fusilli G, Merico G (2011) Hypertriglyceridemic pancreatitis in infant with erysipelas. Eur J Gastroenterol Hepatol 23: 1273. [Crossref]

3. Henter JI, Carlson LA, Hansson M, Nilsson-Ehle P, Ortqvist E (1993) Lipoprotein alterations in children with bacterial meningitis. Acta Paediatr 82: 694-698. [Crossref]

4. Vermont CL, den Brinker M, Ka^keci N, de Kleijn ED, de Rijke YB, et al. (2005) Serum lipids and disease severity in children with severe meningococcal sepsis. Crit Care Med 33: 1610-1615. [Crossref]

Copyright: (C2018 Jouari OEL. This is an open-access article distributed under the terms of the Creative Commons Attribution License, which permits unrestricted use, distribution, and reproduction in any medium, provided the original author and source are credited. 